\title{
Ecotoxicological characterisation of a mycoherbicide mixture isolated from the fungus Ascochyta caulina
}

\author{
Pietro Fumagalli, ${ }^{a}$ Anna Andolfi, ${ }^{b}$ Fabiana Avolio, ${ }^{b}$ Angela Boari, ${ }^{c}$ \\ Alessio Cimmino ${ }^{\mathrm{b}}$ and Antonio Finizio ${ }^{\mathrm{a} *}$
}

\begin{abstract}
BACKGROUND: Recent studies have highlighted the possibility of using a mixture of three fungal toxins produced by Ascochyta caulina as a bioherbicide to control noxious weeds. However, to assess the commercial potential of this new bioherbicide, it is necessary to increase knowledge regarding the environmental behaviour of these toxins, and particularly their effects on non-target organisms. A negative ecotoxicological profile of this potential bioherbicide could eventually hinder its registration.

RESULTS: In this study, acute and chronic effects of the A. caulina toxins (ACTs) on non-target organisms were evaluated in the laboratory. The $(96 \mathrm{~h})$ calculated algal $E_{r} C_{50}$ and NOEC were 142.7 and $<12.5 \mathrm{mg} \mathrm{L}^{-1}$ respectively. For daphnids, the $\mathrm{EC}_{50}$ ( $48 \mathrm{~h}$, acute test) was $20.1 \mathrm{mg} \mathrm{L}^{-1}$, whereas the NOEC ( 21 day chronic reproduction test) was $6.3 \mu \mathrm{g} \mathrm{L}^{-1}$. No cases of mortality, sublethal effects or abnormalities were observed in the acute and chronic tests for Brachydanio rerio at a concentration of $100 \mathrm{mg} \mathrm{L}^{-1}$, indicating a low toxicity of ACTs for this organism. The calculated LC Lo (14 days, acute test) and NOEC (56 day chronic reproduction) for earthworms were $>1000$ and $\geq 250 \mathrm{mg} \mathrm{kg}^{-1}$ soil respectively.

CONCLUSIONS: The present study has provided baseline information needed to assess the potential hazard of the fungal toxins of $A$. caulina. In particular, the acute and chronic effects on aquatic (algae, Daphnia and fish) and terrestrial organisms (earthworms) have been highlighted. Finally, a comparison of the inherent toxicity of ACTs with other synthetic herbicides has shown comparative ecotoxicity of the tested mixture.
\end{abstract}

(c) 2012 Society of Chemical Industry

Keywords: Ascochyta caulina; weed biocontrol; phytotoxins; natural herbicides; ecotoxicology

\section{INTRODUCTION}

In agriculture, plant protection products (PPPs) are utilised worldwide to reduce crop losses due to diseases, pests and weeds, while biocides represent a range of products that are widely utilised in households, industries and public places. Both PPPs and biocides can be of synthetic or biological origin, with the former still representing the largest segment of the global market. ${ }^{1}$ The control of pests, diseases and weeds is mainly achieved by using synthetic products. ${ }^{2}$ However, the use of xenobiotic compounds has raised social and political concern because of their negative effects on human health and natural ecosystems. In this context, many countries have undertaken regulatory changes on PPPs and biocides (e.g. the EU Directives 91/414/EEC and $98 / 8 / E C)$. In the agricultural sector, this has largely influenced the global market of pesticides. Indeed, several old products have been withdrawn from the market, reorienting the practice of crop protection to a more rational use of PPPs, favouring those more selective, less toxic and with minimum environmental impact. ${ }^{3,4}$ A similar situation exists in the field of biocides. ${ }^{5}$ In this context, there has been a strong interest in the development of PPPs and biocides of biological origin (biopesticides). These compounds are generally considered to be less harmful to the environment, as they could display little or no non-target toxicity. ${ }^{6}$
According to USEPA, biopesticides are certain types of pesticide derived from natural materials such as animals, plants, bacteria and certain minerals. ${ }^{7}$ In the field of weed biocontrol, some studies have highlighted the potential use of toxins produced by some phytopathogenetic species of the genus Ascochyta..$^{8-10}$ In particular, A. caulina produces low-molecular-weight hydrophilic phytotoxins (ascaulitoxin, its aglycone and 4-aminoproline) in liquid culture. These toxins have been chemically characterised, and their relative configurations have also been determined. ${ }^{11-14}$ Preliminary results revealed a very high phytotoxicity of these metabolites on noxious weeds, and particularly on Chenopodium album L. (common lambsquarters or fat-hen). ${ }^{15}$ This organism is

\footnotetext{
* Correspondence to: Antonio Finizio, Department of Environmental Sciences, University of Milano Bicocca, Piazza della Scienza, Milan, Italy.

E-mail: antonio.finizio@unimib.it

a Department of Environmental Sciences, University of Milano Bicocca, Milan, Italy

b Dipartimento diScienze del Suolo, della Pianta, dell'Ambiente e delle Produzioni Animali, Università di Napoli Federico II, Portici, Italy

c Istituto di Scienze delle Produzioni Alimentari, CNR, Bari, Italy
} 
one of the most successful colonising species and is a troublesome weed in several crops. ${ }^{16-18}$ It is currently controlled by synthetic compounds, but it is relatively tolerant or resistant to many herbicides in maize and some vegetables. ${ }^{19}$ Furthermore, its management is particularly difficult in areas designated for civil or industrial use, where the use of synthetic chemicals is often prohibited and where the use of other techniques of control is costly and difficult to apply.

The promising results obtained in weed control made these bioactive metabolites a good candidate for the development of a potential mycoherbicide. ${ }^{20}$ Recently, the Regional Governorate of Lombardy (Italy) funded the ECOVIA project (ECOVIA: Development and Pre-industrialisation of an Environmentally Sound Natural Herbicide) in view of a potential request of registration of the $A$. caulina extracts. As a part of the project, a work package entirely devoted to the assessment of acute and chronic effects of the $A$. caulina toxins (ACTs) on aquatic (algae, Daphnia and fish) and terrestrial organisms (earthworms) was planned. In this paper, the results obtained are presented. Furthermore, a comparison of their inherent toxicity with other synthetic herbicides utilised in controlling C. album is also reported.

\section{MATERIALS AND METHODS}

\subsection{Fungal strain, culture medium and growth conditions}

The strain of Ascochyta caulina used in this work for the production of the mixture of toxins is the standard strain used also in the studies previously cited, deposited in the Mycological Collection of the Istituto di Scienze delle Produzioni Alimentari, CNR, Bari, Italy (item 1058, also named AC1 throughout the text). The fungal strain was maintained routinely on potato dextrose agar medium. For the production of culture filtrates, a mineral defined medium (named M1-D) was used for static conditions. ${ }^{21,22}$

\subsection{Purification of toxins}

The mixture of A. caulina toxins (Fig. 1) was purified from the fungal culture filtrates as previously reported. ${ }^{13}$ Briefly, the purification of a large amount of toxin mixture was performed using a glass chromatography column $(90 \times 6 \mathrm{~cm}$ i.d.) loaded with $2 \mathrm{~kg}$ Dowex50 resin. The culture filtrate $(20 \mathrm{~L})$ was lyophilised, dissolved in $750 \mathrm{~mL}$ of distilled $\mathrm{H}_{2} \mathrm{O}$ and acidified to $\mathrm{pH} 2$ with $1 \mathrm{M}$ formic acid. This solution was loaded on the column, which was then eluted as reported above, first with distilled $\mathrm{H}_{2} \mathrm{O}(2 \mathrm{~L})$ and then with $1 \mathrm{M}$ $\mathrm{NH}_{4} \mathrm{OH}(1 \mathrm{~L})$. The basic eluate work-up, as previously reported, gave $8.5 \mathrm{~g}$ of toxin mixture. ${ }^{23}$ The mean composition of the ACT mixture utilised during the ecotoxicological tests was: ascaulitoxin $198.3 \pm 2.1 \mathrm{mg} \mathrm{L}^{-1}$, ascaulitoxin aglycone $105 \pm 2.3 \mathrm{mg} \mathrm{L}^{-1}$, trans4-aminoproline $98 \pm 1.8 \mathrm{mg} \mathrm{L}^{-1}$.

\subsection{Bioassays}

\subsubsection{Toxicity testing for freshwater organisms}

Stock solutions of ACTs were prepared immediately prior to use by dissolving the test substance directly in laboratory-grade distilled water. Stock solutions were diluted to provide a geometric series of test nominal concentrations. The stability of the mixture components in water was confirmed in a different study (Evidente A, private communication).

\subsubsection{Green alga toxicity tests}

The algal growth inhibition test was performed according to the OECD 201 guidelines using the green alga Pseudokirchneriella
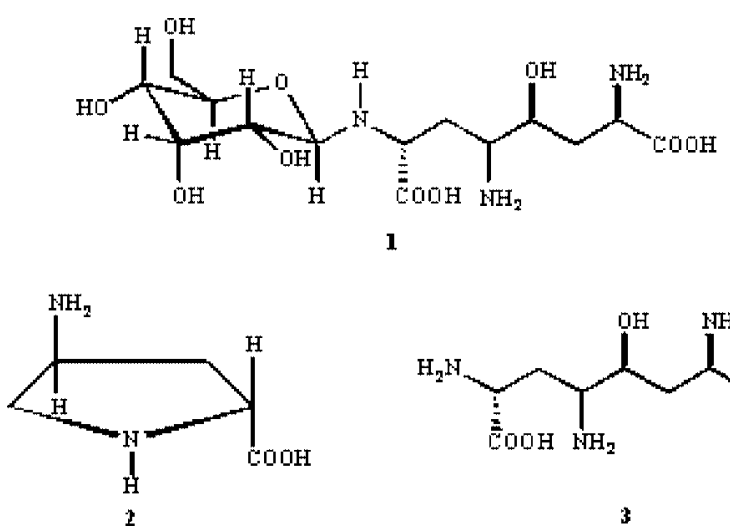<smiles>NC(CC([AlH2])C(=O)O)C(=O)O</smiles>

Figure 1. Structures of ascaulitoxin (1), its aglycone (3) and 4aminoproline (2).

subcapitata in exponential growth phase. ${ }^{24}$ Algal suspension was kept in a culture medium in sterile $250 \mathrm{~mL}$ Erlenmeyer flasks with a temperature of $23 \pm 2{ }^{\circ} \mathrm{C}$ and constant illumination at approximately 4300 lux and stirred with an electrical stirrer. A range-finding test and two definitive tests were conducted to evaluate toxicity in algae. The range-finding test used six control replicates and two replicates per test concentration. Each definitive test used six control replicates and three replicates per test concentration. At the beginning of the test, five ACT solutions $\left(200,100,50,25\right.$ and $\left.12.5 \mathrm{mg} \mathrm{L}^{-1}\right)$ were inoculated with a cellular density of $10^{4}$ cells $\mathrm{mL}^{-1}$ and kept at a temperature of $23 \pm 2{ }^{\circ} \mathrm{C}$ with constant illumination (fluorescent lamp at approximately 8000 lux) and stirred with an electrical stirrer. After this, at 24, 48 and $72 \mathrm{~h}$, the cellular concentration was determined by means of counting with a Burker chamber (both treated and control organisms); $\mathrm{pH}$ was measured at the beginning and at the end of the assay, as well as the total organic carbon (TOC). The latter was measured using an automatic Sievers ${ }^{\circledR}$ analyser.

\subsubsection{Daphnia magna: acute and reproduction toxicity tests}

The $48 \mathrm{~h}$ daphnid toxicity test was conducted according to OECD test guideline $202 .{ }^{25}$ A total of 120 D. magna Straus clone neonates between 6 and 24 h old were utilised: five daphnids (four replicates) for each of the five tested concentrations $(40,20,10,5$ and $2.5 \mathrm{mg} \mathrm{L}^{-1}$ ) and five animals (four replicates) for control. Culturing and testing conditions were similar, with reconstituted M4 water used as medium. ${ }^{26}$ Dissolved oxygen was greater than $60 \%$ of air saturation, temperature was in the range $20 \pm 2{ }^{\circ} \mathrm{C}$, whereas $\mathrm{pH}$ was quite stable during the experiments (mean $\mathrm{pH}$ range 7.80 at the beginning of the test, 8.30 at the end). The TOC was measured by an automatic Sievers ${ }^{\circledR}$ analyser.

Daphnids were kept without light, aeration and unfed for the whole length of the assay. Observations were carried out at 0 , 24 and $48 \mathrm{~h}$ in order to determine the number of immobilised daphnids in each test solution.

The chronic toxicity of ACTs to D. magna Straus clone- 5 was assessed in a 21 day static daily renewal test according to OECD test guideline $211 .{ }^{27}$ First-instar daphnids, between 6 and $24 \mathrm{~h}$ old, were randomly assigned to the test chambers. During the breeding, daphnids were kept in reconstituted water $\left(20 \pm 2{ }^{\circ} \mathrm{C}\right.$, 16:8 $\mathrm{h}$ light:dark, water hardness $<250 \mathrm{mg} \mathrm{CaCO}_{3} \mathrm{~L}^{-1}$ ) fed daily with a diet of both $P$. subcapitata and S. cerevisiae. During the assay, individuals $<24 \mathrm{~h}$ old were kept in reconstituted water $\left(20 \pm 2{ }^{\circ} \mathrm{C}, 16: 8 \mathrm{~h}\right.$ light:dark, water hardness $>140 \mathrm{mg} \mathrm{CaCO}_{3} \mathrm{~L}^{-1}$; 
dissolved $\left.\mathrm{O}_{2}>3 \mathrm{mg} \mathrm{L}^{-1}\right)$ and fed with $P$. subcapitata $\left(0.5 \mathrm{~mL}^{\text {day }}{ }^{-1}\right.$ of a solution of $9.0 \mathrm{E}^{6}$ cells $\left.\mathrm{mL}^{-1}\right)$ and S. cerevisiae $\left(0.4 \mathrm{~mL}^{\text {day }}{ }^{-1}\right.$ of a solution of $5 \mathrm{~g} \mathrm{~L}^{-1}$ ). After a range-finding test, the final test was performed by considering the following nominal concentrations: $100,50,25,12.5$ and $6.3 \mu \mathrm{gL}^{-1}$. A total of $60 \mathrm{D}$. magna were used: 50 of them were treated with the test substance and ten were used as control. Animals were kept under observation for a period of 21 days. The immobilisation and/or other effects were measured every $24 \mathrm{~h}$; the offspring were counted and removed daily; the numbers of aborted eggs and dead offspring were also recorded.

\subsubsection{Fish acute and chronic toxicity tests}

The zebrafish, Brachydanio rerio, was tested in a $96 \mathrm{~h}$ static test according to OECD test guideline $203 .{ }^{28}$ The water used for the assay was left standing for $48 \mathrm{~h}$ greatly to reduce the presence of chlorine. Tanks were controlled for $T\left(23 \pm 0.2^{\circ} \mathrm{C}\right), \mathrm{pH}(8.1$ at the beginning of the test and 8.37 at the end), hardness $(240 \mathrm{mg}$ $\left.\mathrm{CaCO}_{3} \mathrm{~L}^{-1}\right)$ and dissolved $\mathrm{O}_{2}(>70 \%$ of saturation in control and treated). The TOC was measured by an automatic Sievers ${ }^{\circledR}$ analyser. Organisms, seven for each group, were added to the tanks with a biomass density of $<1 \mathrm{~g} \mathrm{~L}^{-1}$. During the acclimatisation period, fish were fed 3 times a week, but the feeding was stopped $24 \mathrm{~h}$ before testing. A preliminary initial test sample was prepared at a concentration of $100 \mathrm{mg} \mathrm{L}^{-1}$ of the active principle in dilution water. The treated groups and the control were observed for $96 \mathrm{~h}$. After the first 2 and $4 \mathrm{~h}$ and at intervals of $24 \mathrm{~h}$, the organisms were observed in order to verify abnormalities such as equilibrium loss, irregular swimming, difficulties in respiratory functions and variations in pigmentation. At the different observation intervals, $\mathrm{pH}$, dissolved $\mathrm{O}_{2}$ and water temperature were recorded.

Based on the results obtained in the acute toxicity test, a zebrafish juvenile growth test was performed under semi-static (daily water renewal) conditions and in compliance with OECD test guideline $215 .^{29}$ Also in this case, a preliminary experiment was carried out at a concentration of $100 \mathrm{mg} \mathrm{L}^{-1}$. The experiment was performed in triplicate (in $5 \mathrm{~L}$ vessels) with 20 individuals, both for the treated groups and for controls. Before the test, fish were held for 2 weeks under the same conditions of water quality $(\mathrm{pH} 7.8$, $T=23 \pm 0.2{ }^{\circ} \mathrm{C} ; 210 \mathrm{mg} \mathrm{CaCO} \mathrm{L}^{-1}$ ), light (photoperiod $=12 \mathrm{~h}$ ), dissolved $\mathrm{O}_{2}(>60 \%)$ and feed $\left(4 \% \mathrm{bw}_{\text {day }}{ }^{-1}\right.$ with dried Artemia salina) as those used in the test. Food was withheld from the fish for $24 \mathrm{~h}$ prior to weighing. Fish were temporarily anaesthetised using 3 -aminobenzoic acid ethyl ester ( $300 \mathrm{mg} \mathrm{L}^{-1},<1$ min duration), gently blotted to remove excess moisture and weighed on a balance. The initial average weight of fish used in the experiment was $61.7 \mathrm{mg}$, with a standard deviation (SD) of $7.2 \mathrm{mg}(11.6 \%)$. After they had been weighed, fish were placed in test chambers for 28 days. Fish were not fed on days 13 and 27 and were reweighed on days 14 and 28 using the previously described procedures. The specific growth rates were then calculated according to the OECD guideline $215 .^{29}$

\subsubsection{Earthworms (Eisenia foetida): toxicity tests}

The earthworm acute toxicity test was conducted according to OECD test guideline 207. ${ }^{30}$ The culture of Eisenia foetida was obtained from a commercial earthworm breeding plant. The artificial soil was composed according to OECD guideline 207: $70 \%$ sand, $20 \%$ kaolin clay and $10 \%$ finely ground Sphagnum peat, adjusted to $\mathrm{pH} 6$ with $\mathrm{CaCO}_{3}$. The dry constituents were blended in the correct proportions and mixed thoroughly. The moisture content was then determined by drying a small sample at $105^{\circ} \mathrm{C}$ and reweighing. Deionised water was then added to reach an overall moisture content of $35 \%$ of the dry weight. The test containers were glass beakers covered with perforated plastic film. For each test, $750 \mathrm{~g}$ weight of the test medium was placed into each glass container with ten earthworms, which were conditioned for $24 \mathrm{~h}$ in artificial soil and washed quickly before testing. During the test period (14 days), adult earthworms (mean weight $462 \pm 12.6 \mathrm{mg}$ ) were held in a controlled chamber ( $20 \pm 2{ }^{\circ} \mathrm{C}$, light intensity 600 lux). After 7 and 14 days, earthworms were weighed and mortality was assessed. The test substance was dissolved in water and added to soil to give a geometric series of concentrations ranging from $10 \mu \mathrm{g} \mathrm{kg}^{-1}$ to $1 \mathrm{~g} \mathrm{~kg}^{-1} \mathrm{dw}$ (four replicates for each treatment and control).

The procedures outlined in OECD guideline 222 were utilised to evaluate the effects of the ACTs on earthworm reproduction. ${ }^{31}$ The artificial soil used in the test was similar in composition to that utilised for the acute test. Adult worms ( $E$. foetida) with a homogeneous age ( 6 months) and clitellum were selected. They were acclimatised ( 1 day) in the artificial soil and fed before testing. Groups of ten worms were washed (deionised water), weighed individually and randomly assigned to the test containers at the start of the test (mean wet mass of individuals $450 \mathrm{mg}$ ). A water solution of the test substance was mixed into the soil. During the test period, earthworms were held in a controlled chamber $\left(20 \pm 2{ }^{\circ} \mathrm{C}\right.$, light intensity 600 lux, 16:8 h light:dark). The water content of the soil substrate was kept constant during the test period. The tested concentrations were 1000, 500, 250, 125 and $62.5 \mathrm{mg} \mathrm{kg}^{-1}$ soil $\mathrm{dw}$. The experiment was performed (in $500 \mathrm{~g}$ dry mass artificial soil) with ten individuals, both for the treated groups (four replicates) and for the controls (eight replicates). On day 28 the earthworms were observed, counted, washed and weighed. At the end of the second 4 week period, the number of juveniles hatched from the cocoons and the number of cocoons were determined as described in Annex 5 of OECD guideline $222 .^{31}$

\subsection{Data treatment}

The determination of the $\mathrm{EC}_{10}, \mathrm{EC}_{50}$ (D. magna), $\mathrm{LC}_{50}$ (E. foetida) and $\mathrm{E}_{\mathrm{r}} \mathrm{C}_{50}$ ( $P$. subcapitata growth rate) values (together with $95 \%$ fiducial limits) was conducted using the USEPA probit analysis program (v.1.5). The LOEC and hence the NOEC for the algal growth inhibition test were determined by ANOVA (Dunnett's test, $P=0.05$ ). The homogeneity and normality of the dataset were evaluated before the ANOVA test. Similar methodology was applied for the D. magna chronic tests and the earthworm reproduction tests.

\section{RESULTS}

\subsection{Effects on growth of algal organisms}

The $72 \mathrm{~h} P$. subcapitata study examined the algal growth rate as an assessment endpoint. The quality criteria for the test were satisfied. In fact, the cell concentration in the control culture increased by a factor $>16$ in 3 days, corresponding to a specific growth rate of 0.92 day $^{-1}$. When compared with the control, there was no significant reduction in $P$. capitata cell growth in the first $24 \mathrm{~h}$. Subsequently, all the tested concentrations exhibited an inhibition of cell growth (Fig. 2). After $72 \mathrm{~h}$ at the highest tested concentration ( $\left.200 \mathrm{mg} \mathrm{L}^{-1}\right)$, the calculated growth inhibition was $61.4 \%$. The calculated algal $\mathrm{E}_{\mathrm{r}} \mathrm{C}_{50}$ was $142.7 \mathrm{mg} \mathrm{L}^{-1}$ and the LOEC was $12.5 \mathrm{mg} \mathrm{L}^{-1}$ (NOEC was not determined in this test). 




Figure 2. Effect of $A$. caulina toxins (ACTs) on growth of $P$. subcapitata during a $72 \mathrm{~h}$ study.

\begin{tabular}{|c|c|c|c|c|c|c|c|c|}
\hline \multirow{3}{*}{$\begin{array}{l}\text { Nominal } \\
\text { concentration } \\
\left(\mathrm{mg} \mathrm{L}^{-1}\right)\end{array}$} & \multicolumn{8}{|c|}{ Number immobile/number at test start ${ }^{\mathrm{a}}$} \\
\hline & \multicolumn{4}{|c|}{$24 \mathrm{~h}$} & \multicolumn{4}{|c|}{$48 \mathrm{~h}$} \\
\hline & A & B & $\mathrm{C}$ & $\mathrm{D}$ & A & B & $\mathrm{C}$ & $\mathrm{D}$ \\
\hline 0 & $0 / 5$ & $0 / 5$ & $0 / 5$ & $0 / 5$ & $0 / 5$ & $0 / 5$ & $0 / 5$ & $0 / 5$ \\
\hline 2.5 & $0 / 5$ & $0 / 5$ & $0 / 5$ & $0 / 5$ & $0 / 5$ & $0 / 5$ & $0 / 5$ & $0 / 5$ \\
\hline 5 & $0 / 5$ & $0 / 5$ & $0 / 5$ & $0 / 5$ & $0 / 5$ & $0 / 5$ & $0 / 5$ & $0 / 5$ \\
\hline 10 & $0 / 5$ & $0 / 5$ & $0 / 5$ & $0 / 5$ & $1 / 5$ & $0 / 5$ & $1 / 5$ & $0 / 5$ \\
\hline 20 & $0 / 5$ & $0 / 5$ & $0 / 5$ & $0 / 5$ & $3 / 5$ & $2 / 5$ & $2 / 5$ & $3 / 5$ \\
\hline 40 & $0 / 5$ & $0 / 5$ & $0 / 5$ & $0 / 5$ & $5 / 5$ & $5 / 5$ & $4 / 5$ & $4 / 5$ \\
\hline
\end{tabular}

\subsection{Effects on Daphnia magna}

Both acute and chronic tests were performed on D. magna according to standard protocols. The quality criteria for both the tests were satisfied. In the acute toxicity test, the immobilisation of daphnids in control vessels was $<10 \%$ at the end of the test, and the concentration of dissolved oxygen and $\mathrm{pH}$ were within the required ranges. In the chronic test, the control mortality was $0 \%$ during the test, and mean control reproduction was 80 neonates per parent daphnid surviving to study termination. Furthermore, the coefficient of variation in the control was $9.5 \%$.

In the first $24 \mathrm{~h}$, no acute effects were recorded (0\% D. magna immobility) both in the control and with all the tested nominal concentrations. After $48 \mathrm{~h}$, the highest concentration resulting in no immobilisation was $5 \mathrm{mg} \mathrm{L}^{-1}$, whereas at concentrations of 10 , 20 and $40 \mathrm{mg} \mathrm{L}^{-1}$ the immobilisation observed was 10,50 and $90 \%$ respectively (Table 1$)$. The calculated $\mathrm{EC}_{10}$ and $\mathrm{EC}_{50}(48 \mathrm{~h})$ values of the acute daphnid test were $10.2(6.5-13.1)$ and $20.1 \mathrm{mg} \mathrm{L}^{-1}$ (95\% Cl: 16.3-25.1) respectively.

A preliminary range-finding chronic reproduction test was performed. Parent organisms were found dead in all tested concentrations, with the exception of the lowest concentration $\left(2.5 \mu \mathrm{g} \mathrm{L}^{-1}\right)$, in which two organisms survived throughout the test; they produced 16 and 14 live offspring respectively. The results of the final daphnid chronic reproduction test are given in Table 2. Calculation of study endpoints was based on the nominal test concentrations of ACTs.
Table 2. Summary of data from a 21 day Daphnia magna life cycle toxicity test with ACTs. An asterisk indicates a statistically significant effect $(P=0.05)$ relative to the control ${ }^{a}$

Geometric mean nominal

ACT concentration

$(\mathrm{CV} \%, n=9.5)$

Adult

survival (\%)

Total number

Control

$6.3 \mu \mathrm{g} \mathrm{L}^{-1}$

$12.5 \mu \mathrm{g} \mathrm{L}^{-1}$

$25 \mu \mathrm{g} \mathrm{L}^{-1}$

$50 \mu \mathrm{g} \mathrm{L}^{-1}$

$100 \mu \mathrm{gL}^{-1}$

$\begin{array}{cc}100 & 80(7.0) \\ 100 & 74(4.7) \\ 100 & 54(5.7) \\ 80 & 36(3.4) \\ 70 & 19^{*}(2.2) \\ 40 & 22^{*}(1.1)\end{array}$

${ }^{\text {a }}$ Number of replicates $=10$ for all treatments.

A significant mortality was observed in parent daphnids during the test at the highest tested concentrations. The calculated $\mathrm{ACT} 21$ day $\mathrm{EC}_{50}$ and $\mathrm{EC}_{10}$ values based on immobility of parent daphnids were 76 and $22.5 \mu \mathrm{g} \mathrm{L}^{-1}$ respectively. The time to first brood and the number of broods of neonates were measured as indicators of reproductive performance. The first brood occurred between days 8 and 10 of the test. Apparently, the highest concentrations of 50 and $100 \mu \mathrm{g} \mathrm{L}^{-1}$ induced a little delay in the appearance of the first brood. ACTs caused a decrease in the average number of offspring per parent organism surviving to test termination. In fact, the mean number of neonates per surviving parent daphnid at 21 days decreased in a concentration-related manner from 80 in the control to 19-22 at the highest two ACT concentrations. Control reproduction after 21 days was within the range of the historical reproduction data for the laboratory performing the test. Neonate production, as a percentage of the control value, was 92, 67, 45, 24 and $27 \%$ at 6.3, 12.5, 25, 50 and $100 \mathrm{~g} \mathrm{~L}^{-1}$ respectively. The 21 day NOEC and LOEC, based on the number of live neonates per surviving parent daphnid, were 6.3 and $12.5 \mu \mathrm{g} \mathrm{L}^{-1}$ of ACTs respectively.

\subsection{Effects on fish}

No cases of mortality or sublethal effects (equilibrium loss, changes in swimming, respiration, pigmentation or feeding) were detected in the acute limit test $\left(100 \mathrm{mg} \mathrm{L}^{-1}\right)$ for $B$. rerio, indicating a low acute toxicity of ACTs for this organism. The quality criteria were fulfilled, as no mortality in the control test was recorded and the dissolved oxygen concentration during the $96 \mathrm{~h}$ was always $>70 \%$. Therefore, the $96 \mathrm{~h} \mathrm{LC}_{50}$ and NOEC were $>100 \mathrm{mg} \mathrm{L}^{-1}$, based on the nominal ACT concentrations and mortality or sublethal effects.

The ACTs seem not to show any chronic effects on $B$. rerio up to concentrations of $100 \mathrm{mg} \mathrm{L}^{-1}$. In the 28 day test, no mortality or abnormalities were observed during the test period. Furthermore, control fish increased in weight by 19.7 and 38\% after 14 and 28 days respectively. There was an increase of 18.6 and $42 \%$ in fish exposed to $100 \mathrm{mg} \mathrm{L}^{-1}$ (ACT nominal concentrations) after days 14 and 28 respectively. On the basis of the results obtained in this preliminary test, a 28 day NOEC for growth and mortality of $\geq 100 \mathrm{mg} \mathrm{L}^{-1}$ can be assumed.

\subsection{Effects on earthworms}

No mortality was found in soil contaminated with ACTs and controls up to the highest tested concentration for the duration of the experiment (14 days). Loss of weight was not observed, either 


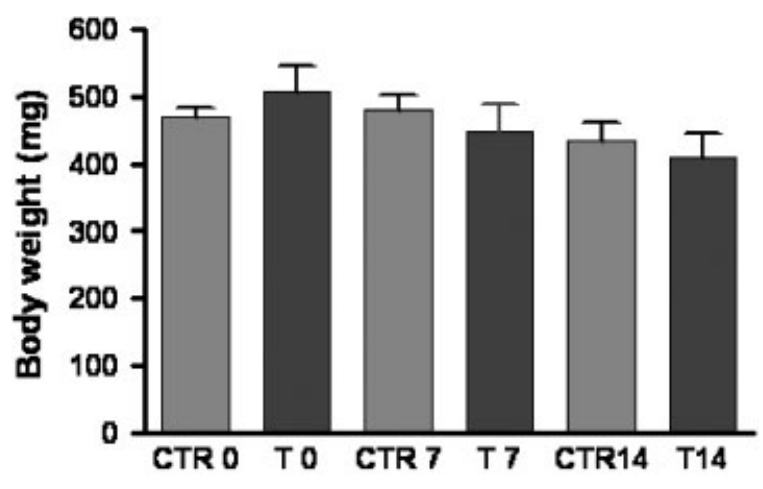

Figure 3. Body weight at different time intervals $(0,7$ and 14 days) in control (CTR) and treated (T) earthworms (ACTs $=1000 \mathrm{mg} \mathrm{kg}^{-1} \mathrm{dw}$ ).

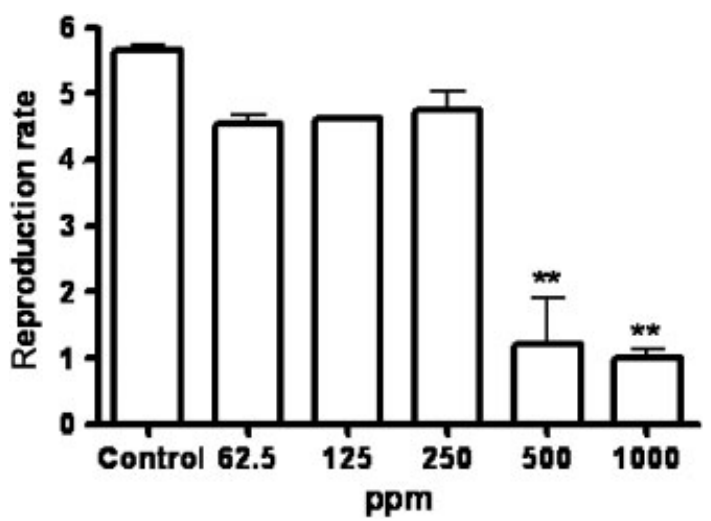

Figure 4. Reproduction rate in controls and in tested concentrations.

at 7 or at 14 days after exposure (Fig. 3). On this basis, the 14 day $\mathrm{LC}_{50}$ and NOEC for ACTs is $\geq 1000 \mathrm{mg} \mathrm{kg}^{-1}$ soil, based on nominal ACT concentrations and mortality or sublethal effects.

In the earthworm reproduction test, after 28 days, no mortality or pathological symptoms and no significant changes in body weight of living adults were found in any test container. On the other hand, ACTs showed significant effects on E. foetida reproduction rate (mean number of juvenile worms produced per number of adults over the test period) at the highest tested concentrations (Fig. 4). The reproduction rate was reduced by exposure to ACT nominal concentrations of 500 and $1000 \mathrm{mg} \mathrm{kg}^{-1}$ soil. As $500 \mathrm{mg} \mathrm{kg}^{-1}$ soil of ACTs had a significant effect on earthworm reproduction, the NOEC ( 56 days) for ACTs on earthworm reproduction was $\geq 250 \mathrm{mg} \mathrm{kg}^{-1}$ soil.

\section{DISCUSSION}

The introduction of new regulations in the field of chemical risk management during past years has led to changes in the market of pesticides and biocides. For instance, specific rules have been developed in organic farming to define which substances are allowed to be used (no synthetic products). Furthermore, the EU Directive 91/414/EEC has established harmonised criteria for placing new PPPs on the market and for re-registering those active ingredients already commercialised. This directive has also provided the establishment of a positive list of active substances (Annex I) containing all the substances that, after an appropriate analysis of possible risks (both for human health and for the environment), are considered safe to use. Only substances included in Annex I can be commercialised. The review of existing pesticides has led to the removal of several from the market. Many active ingredients have been eliminated because registration dossiers were not submitted, incomplete or withdrawn by industry. ${ }^{32}$ This has led to a large reduction in chemical alternatives for pest and weed control. For instance, in the last few years, at least nine active ingredients widely used for controlling C. album have been excluded from Annex I.

Recently, the new Regulation 1107/2009/EC has replaced Directive 91/414/EC. It has established some new criteria for registration of PPPs and has introduced the comparative risk assessment (Art. 50 of Regulation 1107/2009) approach. The aim is to verify whether the active ingredients can be replaced with alternatives that, while being sufficiently efficacious and not causing unreasonable economic or practical disadvantages for the users, can be considered safer for humans and for the environment. The same is happening in the field of biocides with the imminent revision of Directive 98/8/EC. A prerequisite for substitution is the presence of a significant difference between the potential risks to human health and the environment. ${ }^{33}$ The traditional environmental risk assessment procedures for pesticides are based on the toxicological exposure ratio (TER), that is, the ratio between well-defined toxicological endpoints on non-target organisms and the measured/predicted levels of exposure in different environmental compartments. ${ }^{34}$ The degree of risk will be related both to components of the TER and to the effectiveness of the substance in weed control. However, as a preliminary screening to evaluate the potential candidature of ACTs as a mycoherbicide, it can be useful to compare their inherent toxicity with other herbicides (already present on the market) that are considered effective towards $C$. album. The results of this comparison are shown in Fig. 5, where the acute and chronic (log scale) toxicity data of ACTs (this study) are reported together with those available for other synthetic herbicides commonly used on C. album. ${ }^{35}$ In the algal toxicity test, it was not possible to determine the NOEC of ACTs. For this reason, in order to allow the comparison, the NOEC for algae was extrapolated by applying to the LOEC $\left(12.5 \mathrm{mg} \mathrm{L}^{-1}\right)$ a safety factor of 10 . Consequently, a NOEC of $1.25 \mathrm{mg} \mathrm{L}^{-1}(\log$ NOEC $=0.09)$ is considered in Fig. 4. The application of a safety factor of 10 was regarded as adequately protective for NOEC extrapolation by considering that generally the median acute chronic toxicity ratio (ACR) for algae is 5.4. ${ }^{36}$

The results reported in Fig. 5 indicate a quite good ecotoxicological profile of ACTs. The general trend of acute and chronic toxicity across taxa indicate that the ACT mixture is the active ingredient with the best performance (with the exception of D. magna). From Fig. 5, the following points can be made:

- Acute toxicity. ACTs show the lowest acute toxicity on algae, fish (with the partial exception of metamitron) and earthworms. This is particularly true for primary producers; for these organisms, the acute toxicity of ACTs is significantly lower than that of the other herbicides considered (even by several orders of magnitude). On the other hand, the comparison of acute toxicity values on Daphnia indicates insignificant differences among the substances.

- Chronic toxicity. Again, the ACTs show the lowest toxicity on most aquatic organisms. Unfortunately, the ACTs show the worst performance on daphnids. As ACTs are natural substances, they could be rapidly degradable in the environment, reducing the risk of chronic exposure of aquatic organisms. Unfortunately, data on the persistence of these substances are not yet available. 

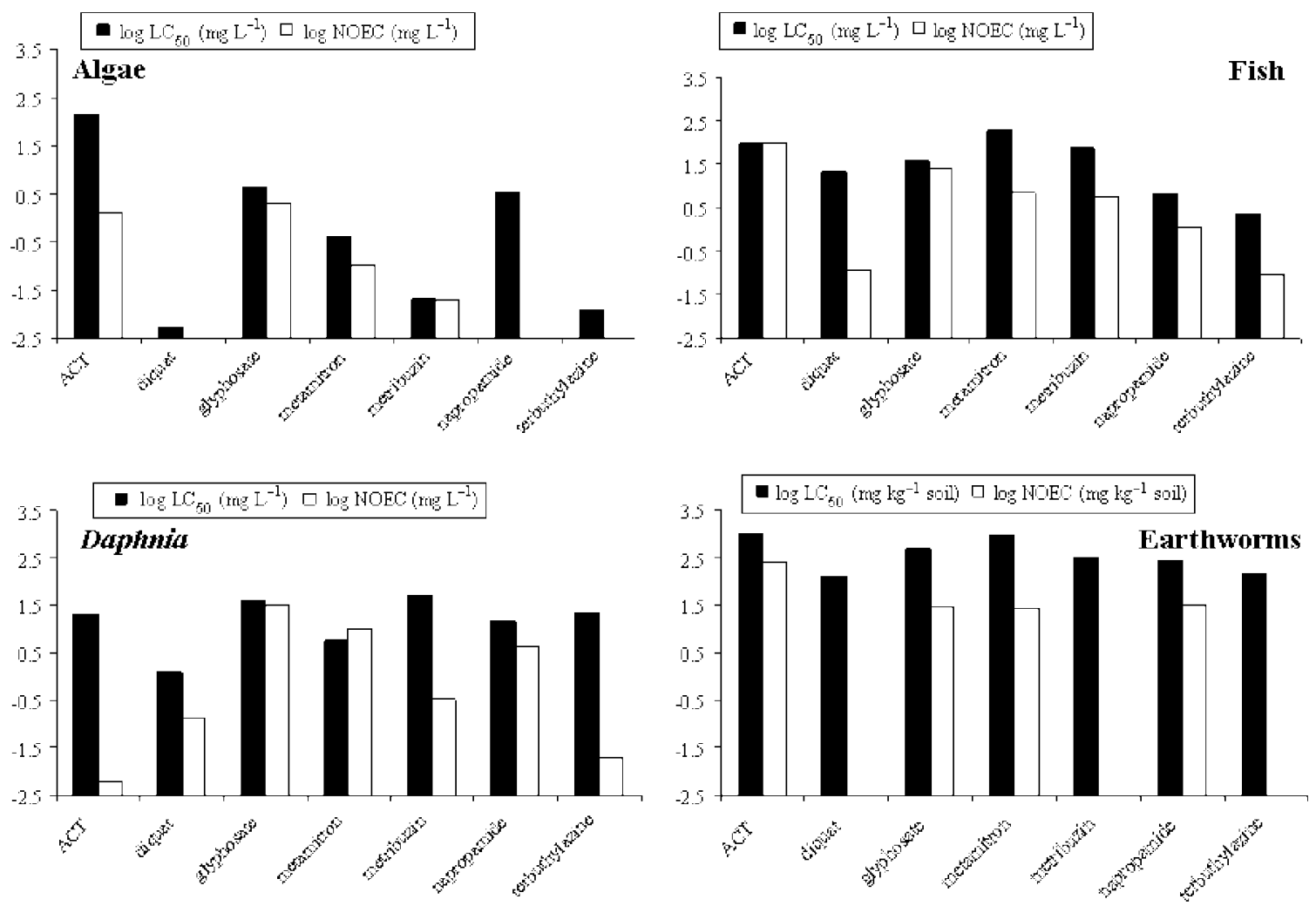

Figure 5. Comparison of the inherent toxicity on non-target organisms among ACTs and different herbicides utilised to control C. album, represented as $\log \mathrm{LC}_{50}$ and log chronic NOEC. The asterisk indicates that no toxicity was observed at this concentration.

\section{CONCLUSIONS}

In this study, the ecotoxicological profile of ACTs produced by $A$. caulina was investigated both on aquatic (algae, Daphnia, fish) and terrestrial organisms (earthworms). With the exception of $D$. magna, the aquatic organisms were not particularly sensitive. In fact, for algae and fish, according to the GHS (Globally Harmonised System of Classification and Labelling of Chemicals), the ACTs exceeded both class III and class II, respectively, for the acute and chronic aquatic toxicity categories (not harmful). On the other hand, for Daphnia magna, the ACTs can be categorised in acute class III and chronic class II respectively (hazardous to the aquatic environment). Finally, the results obtained in both acute and chronic toxicity tests with $E$. foetida indicated a very low toxicity of ACTs for terrestrial organisms. In general, the comparison of the ecotoxicological profile of ACTs with other herbicides has shown a lower ecotoxicity for the tested mixture.

\section{ACKNOWLEDGEMENTS}

The authors gratefully acknowledge financial support from the Regional Governorate of Lombardy, who funded the ECOVIA project. They are also grateful to $\mathrm{Dr} M$ Vurro (Istituto di Scienze delle Produzioni Alimentari, CNR, Bari) and Prof. A Evidente (Dipartimento di Scienze del Suolo, della Pianta, dell'Ambiente e delle Produzioni Animali, Università di Napoli) for their helpful comments and suggestions.

\section{REFERENCES}

1 Thakore $Y$, The new biopesticide market. BCC Research Report CHM029B (2006).
2 Zhang WJ, Jiang FB and Ou JF, Global pesticide consumption and pollution: with China as a focus. Proc Int Acad Ecol Environ Sci 1(2):125-144 (2011).

3 Gullino ML and Kuijpers LAM, Social and political implications of managing plant diseases with restricted fungicides in Europe. Annu Rev Phytopathol 32:559-579 (1994).

4 Ragsdale NN and Sisler HD, Social and political implications of managing plant diseases with decreased availability of fungicides in the United States. Annu Rev Phytopathol 32:545- 557 (1994).

5 Bhadury $P$ and Wright PC, Exploitation of marine algae: biogenic compounds for potential antifouling applications. Planta 219:561 - 578 (2004).

6 Russell KH and Susan MB, Research initiatives in the art and science of biopesticide formulations. Soil Biol Biochem 38:845-849 (2006).

7 Regulating Pesticides. What are Biopesticides? [Online]. US Environmental Protection Agency (USEPA), Washington, DC (2008). Available: URL:http://www.epa.gov/pesticides/biopesticides/whatarebiopest icides.htm [4 May 2012].

8 Zonno MC, van Der Zweerde W, Scheepens PC and Vurro M, Potential use of phytotoxic culture filtrates of Ascochyta caulina in integrated control of Chenopodium album. Proc VI Int Mycological Congr, Jerusalem, Israel (1998).

9 Netland J, Dutton LC, Greaves MB, Baldwin M, Vurro M, Evidente A et al., Biological control of Chenopodium album L. in Europe. BioControl 46:211-228 (2001).

10 Upadhyay RK, Kenfield D, Strobel GA and Hess WM, Ascochyta cypericola sp. nov. causing leaf blight of purple nutsedge (Cyperus rotundus). Can J Bot 69:797-802 (1991).

11 Evidente A, Capasso R, Cutignano A, Taglialatela-Scafati O, Vurro $\mathrm{M}$, Zonno MC et al., Ascaulitoxin, a phytotoxic bis-amino acid Nglucoside from Ascochyta caulina. Phytochemistry 48:1131-1137 (1998).

12 Evidente A, Andolfi A, Vurro M, Zonno MC and Motta A, Trans4-aminoproline, a phytotoxic metabolite with herbicidal activity produced by Ascochyta caulina. Phytochemistry 53:231-237 (2000).

13 Evidente A, Andolfi A, Vurro M and Zonno MC, Determination of Ascochyta caulina phytotoxins by high performance anion exchange 
chromatography and pulsed amperometric detection. Phytochem Anal 12:383-387 (2001).

14 Bassarello C, Bifulco G, Evidente A, Riccio R and Gomez-Paloma L, Stereochemical studies on ascaulitoxin: extension of the J-based NMR configurational analysis of a nitrogen substituted system. Tetrahedron Lett 42:8611-8613 (2001).

15 Evidente $A$ and Abouzeid MA, Characterization of phytotoxins from phytopathogenic fungi and their potential use as herbicides in integrated crop management, in Handbook of Sustainable Weed Management, ed. by Singh HP, Batish DR and Kohli RK. The Haworth Press, Inc., New York, NY (2006).

16 Allard R, Genetic systems associated with colonizing ability in predominantly self-pollinated species, in The Genetics of Colonizing Species, ed. by Baker $\mathrm{H}$ and Stebins G. Academic Press, New York, NY (1965).

17 Andreasen C, Streibig JC and Haas H, Soil properties affecting the distribution of 37 weed species in Danish fields. Weed Res 31:181-187 (1991).

18 Holm LG, Plunkett DL, Pancho JV and Herberger J P, The World's Worst Weeds:Distribution and Biology. University of Hawaii Press, Honolulu, HI, USA (1977).

19 Myers MG and Harvey RG, Triazine-resistant common lambsquarters (Chenopodium album L.) control in field corn (Zea mays L.). Weed Technol 7:884-889 (1993).

20 Vurro $M$, Zonno MC, Evidente A, Andolfi $A$ and Montemurro $\mathrm{P}$, Enhancement of efficacy of Ascochyta caulina to control Chenopodium album by use of phytotoxins and reduced rates of herbicides. Biol Control 21:182-190 (2001).

21 Pinkerton F and Strobel GA, Serinol as an activator of toxin production in attenuated cultures of Helminthosporium sacchari. Proc Natl Acad Sci USA 73:4007-4011 (1976).

22 Vurro M, Andolfi A, Boari A, Zonno MC, Caretto S, Avolio F et al, Optimization of the production of herbicidal toxins by the fungus Ascochyta caulina. Biol Control 60:192-198 (2012).

23 Avolio F, Andolfi A, Zonno MC, Boari A, Vurro M and Evidente A, Process for the large scale production and purification of Ascochyta caulina phytotoxins, potential herbicides: a new method for toxins analysis. Chromatographia 74(7/8):633-638 (2011).

24 Guidelines for Testing of Chemicals, No. 201, Freshwater alga and cyanobacteria, growth inhibition test. Organisation of Economic Cooperation and Development (OECD) (2006).
25 Guidelines for Testing of Chemicals, No. 202, Daphnia sp., acute immobilisation test. Organisation of Economic Cooperation and Development (OECD) (2004).

26 Elendt BP and Bias WR, Trace nutrient deficiency in Daphnia magna cultured in standard medium for toxicity testing: effects of the optimization of culture conditions on life history parameters of Daphnia magna. Wat Res 24:1157-1167 (1990).

27 Guidelines for Testing of Chemicals, No. 211, Daphnia magna reproduction test. Organisation of Economic Cooperation and Development (OECD) (1998).

28 Guidelines for Testing of Chemicals, No. 203, Fish acute toxicity test. Organisation of Economic Cooperation and Development (OECD) (1992).

29 Guidelines for Testing of Chemicals, No. 215, Fish juvenile growth test. Organisation of Economic Cooperation and Development (OECD) (2000).

30 Guidelines for Testing of Chemicals, No. 207, Earthworm acute toxicity test. Organisation of Economic Cooperation and Development (OECD) (1984).

31 Guidelines for Testing of Chemicals, No. 222, Earthworm reproduction test. Organisation of Economic Cooperation and Development (OECD) (2004).

32 Cavoski I, Caboni $\mathrm{P}$ and Miano T, Natural pesticides and future perspectives, in Pesticides in the Modern World - Pesticides Use and Management, ed. by Stoytcheva M. InTech, Rijeka, Croatia, pp. 169-190 (2011).

33 Sunley Rand van Opstal N, EPPO workshop on comparative assessment in the framework of substitution. 1: A summary of the conclusions and recommendations. Bull OEPP/EPPO Bull 40:101-104 (2010).

34 Finizio A and Villa S, Environmental risk assessment for pesticides: a tool for decision-making. Environ Risk Assess Rev 22:235-248 (2002).

35 The pesticide properties database (PPDB), Agriculture and Environment Research Unit (AERU), University of Hertfordshire, Hatfield, Herts, UK (2009).

36 Ahlers J, Riedhammer C, Vogliano M, Ebert RU, Kühne R and Schüürmann $\mathrm{G}$, Acute to chronic ratios in aquatic toxicity - variation across trophic levels and relationship with chemical structure. Environ Toxicol Chem 25(11):2937-2945 (2008). 